\title{
EXPOSIÇÕES COMO PATRIMÓNIO. PRESERVAR E DIVULGAR A MEMÓRIA EXPOSITIVA DA FUNDAÇÃO CALOUSTE GULBENKIAN
}

EXHIBITIONS AS HERITAGE: PRESERVING AND DISSEMINATING

THE MEMORY OF THE EXHIBITIONS OF THE CALOUSTE

GULBENKIAN FOUNDATION

Enviado em 17 de março de 2015

Aceito em 16 de junho de 2015

Leonor de Oliveira ${ }^{1}$

Joana Baião

Resumo: A História das Exposições tornou-se num dos temas atualmente mais discutidos e valorizados nos campos da História da Arte e da Museologia. Esta nova disciplina está a contribuir para uma revisão crítica da historiografia da arte, das práticas museológicas e das políticas de promoção artística e valorização patrimonial.

O projeto Catálogo Raisonné Online das Exposições de Arte da Fundação Calouste Gulbenkian insere-se no amplo debate internacional em torno do tema das Exposições, participando numa tendência recente de valorização patrimonial destes eventos e salvaguarda da sua memória.

Para além de dar a conhecer os objetivos, estrutura e metodologia de trabalho deste projeto, este texto pretende ainda explicitar, a partir deste caso específico, os desafios colocados atualmente à valorização e divulgação do património, tendo em conta os variados recursos tecnológicos disponíveis, a dispersão e diversificação de testemunhos relacionados, a necessidade de classificar e de tornar acessível a informação sobre os bens materiais.

Palavras-chave: Exposições. Fundação Calouste Gulbenkian. Documentação e inventariação.

\footnotetext{
1 Graduada em História da Arte, Licenciatura, pela Faculdade de Ciências Sociais e Humanas da Universidade Nova de Lisboa. Mestre em Museologia e Património pela Faculdade de Ciências Sociais e Humanas da Universidade Nova de Lisboa. Doutora em História da Arte - Especialização em Museologia e Património Artístico pela Faculdade de Ciências Sociais e Humanas da Universidade Nova de Lisboa. Membro integrado do Instituto de História da Arte da Faculdade de Ciências Sociais e Humanas da Universidade Nova de Lisboa. E-mail: Icoliveira@gulbenkian.pt

2 Graduada em Artes Plásticas (Escultura), Licenciatura, pela Faculdade de Belas-Artes da Universidade de Lisboa. Mestre em Museologia pela Faculdade de Ciências Sociais e Humanas da Universidade Nova de Lisboa. Doutora em História da Arte - Especialização em Museologia e Património Artístico pela Faculdade de Ciências Sociais e Humanas da Universidade Nova de Lisboa. Investigadora do Instituto de História da Arte da Faculdade de Ciências Sociais e Humanas da Universidade Nova de Lisboa e consultora na Fundação Calouste Gulbenkian.
} 
Abstract: The History of Exhibitions has recently become one of the most discussed and relevant themes in the fields of Art History and Museology. This new discipline is contributing to a critical review of art historiography and museological practices as well as artistic promotion and heritage preservation policies.

The Online Catalogue Raisonné of the Calouste Gulbenkian Foundation's Art Exhibitions isinserted into the larger international debate on Exhibition studies and is participating in the recent process of patrimonialization of these events, as well as preservation of their memory.

This article aims to not only introduce the goals, structure and methodology of the Gulbenkian Exhibitions Project, but also point out the challenges facing heritage promotion in light of today's multiplicity of technological resources, the current dispersion and diversification of documentary sources, as well as the need to classify material heritage information and make it accessible to the public.

Keywords: Exhibitions. Calouste Gulbenkian Foundation. Documentation and inventory.

\section{A HISTÓRIA DAS EXPOSIÇÕES: UMA NOVA DISCIPLINA NA}

\section{HISTÓRIA DA ARTE E MUSEOLOGIA}

As exposições tornaram-se, desde a década de 90 do século passado, verdadeiros casos de estudo para museólogos e historiadores da arte, podendo-se afirmar que, hoje em dia, a história das exposições se tornou num ramo disciplinar da Museologia e História da Arte.

Este tema tem sido transversal ao universo académico e museológico anglosaxónico e francófono e a sua abordagem tem-se diversificado. Ao analisar-se as Exposições Universais, Feiras Internacionais ou Bienais reflete-se também sobre as implicações políticas e diplomáticas, a afirmação nacional ou regional do ponto de vista económico e artístico.

No campo da História da Arte, seleciona-se e destaca-se as exposições que "fizeram a História da Arte", por terem revelado artistas e movimentos marcantes. De um modo mais genérico, as exposições são entendidas como o contexto primordial no qual as obras de arte são pela primeira vez mostradas ao público. A exposição 
determina, por isso, o modo como estas são recebidas e o seu impacto no panorama artístico, na crítica de arte e no mercado.

Por outro lado, à exposição tem sido também reconhecida uma dimensão artística, dado o prestígio dos arquitetos e museógrafos que nela intervêm e a qualidade e atualidade criativa e, por vezes, vanguardista, das museografias propostas.

Finalmente, do ponto de vista político, as exposições têm sido estudadas como reflexo e instrumento das medidas de proteção patrimonial e de apoio às artes, do discurso político, das linhas historiográficas oficiais e da estratégia diplomática.

Tem sido no contexto académico em articulação com os museus de arteque se tem avançado verdadeiramente na valorização da exposição enquanto testemunho e "objeto cultural em si mesmo" (Parcollet; Szacka, 2012, p. 107). Neste momento, o debate em torno das metodologias para a documentação e preservação da memória dos eventos expositivos avançou para uma nova fase, que põe em prática os procedimentos e abordagens definidos anteriormente.

Uma vez quea exposição é um evento efémero, cuja memória se desmultiplica por registos vários, sendo o catálogo um testemunho apenas parcial da sua realização, coloca-se a questão de como preservar e, sobretudo, tornar acessível a sua história e conteúdo, o seu impacto artístico e cultural e, finalmente, o seu valor patrimonial.

Os projetos que se têm dedicado ao estudo sistemático de exposições,optaram por abordá-las enquanto objetos, aproximando-as de criações artísticas como as instalações ou performances, também de natureza efémera e condicionadas pelos locais onde são realizadas. Como consequência, essa sistematização resultou na elaboração de catálogos raisonné.

Um desses projetos já se encontra concluído e foi dedicado às exposições comissariadas pelo reconhecido curador de arte contemporânea, Harald Szeemann: Harald Szeemann with byth rough because towards despite: catalogue of all exhibitions, 1957-2005, editado em 2007.

O outro catálogo raisonné de exposições, cuja organização está ainda em curso, tem o objetivo de sistematizar todas as exposições realizadas pelo Centre Pompidou.

Apesar de visarem protagonistas diferentes, ambos os catálogos raisonné têm como ponto de partida o levantamento e análise de material de arquivo relacionado com cada uma das exposições estudadas. De facto, uma das consequências do processo recente de valorização histórica das exposições prende-se com a igual valorização dos registos documentais a elas associados e, consequentemente, de toda a documentação gerada pela atividade dos museus. O material documental relacionado com as exposições é essencial para traçar o seu processo de conceção e 
organização, determinar o seu verdadeiro impacto e tornar esses eventos visualmente acessíveis no presente através da recolha de registos fotográficos e fílmicos.

Uma das consequências desta nova abordagem da exposição e do material documental gerado pela atividade dos museus é a expansão de um novo conceito: exposições de exposições ou exposições de material de arquivo. A programação do Van Abbemuseum tornou-se uma referência neste campo. Este museu holandês está recriar em contexto expositivo modelos museográficos do passado ${ }^{3}$ e a dinamizar o projeto Living Archive - um programa de exposições que relaciona obras da coleção com a documentação gerada através da sua incorporação e gestão ${ }^{4}$.

\section{DOCUMENTAR AS EXPOSIÇÕES}

\subsection{O PROJETO DO MACBA}

O estudo sistemático das exposições está, por consequência, diretamente relacionado com a atual valorização e organização dos arquivos de museus. Esta nova tendência está também relacionada com a aproximação dos museus ao meio académico e o seu envolvimento crescente com a investigação, como o Museu de Arte Contemporânea de Barcelona (MACBA) exemplifica.

Segundo a direção do MACBA, a importância dada ao arquivo está a "reforçar o papel do museu enquanto centro de investigação e espaço de construção da memória histórica“. O Museu de Barcelona criou, por isso, o seu próprio centro de estudos (o CED), com o objetivo de "promover e enriquecer o papel do Museu enquanto agente de investigação, ligando as atividades expositivas ao estudo e produção de conhecimento no campo da arte contemporânea" (Folding the exhibition, 2014, p.10).

O estudo das exposições produzidas pelo próprio MACBA assumiu papel preponderante no reposicionamento do arquivo na estrutura do museu, permitindo não só o estudo e reabordagem dos objetos da coleção, mas também a criação artística.

Em 2011, o MCBA integrou, através do seu centro de estudos, o projeto europeu MeLA (European Museums in the Age of Migrations) ${ }^{5}$, cabendo-lhe a tarefa de

\footnotetext{
3 Programa Time Machines Reloaded. Disponível em: <http://vanabbemuseum.nl/en/programme /detail/?tx_vabdisplay_pi $1 \% 5 B p t y p e \% 5 D=18 \&$ tx_vabdisplay_pi $1 \% 5 B$ project $\% 5 \mathrm{D}=760 \geq \mathrm{e}$ $<$ http://vanabbemuseum.nl/en/programme/detail/?tx_vabdisplay_pi $1 \% 5 B p t y p e \% 5 \mathrm{D}=18 \&$ tx_vabdisplay_pi 1 \%5Bproject\%5D=692>Acesso em: mar. 2015.

4 Disponível em:<http://vanabbemuseum.nl/en/programme/detail/?tx_vabdisplay_pi $1 \% 5 B p t y p e \% 5 D=18 \& t x$ _vabdisplay_pi1\%5Bproject\%5D=544>. Acesso em: mar. 2015.

$5<$ www.mela-project.eu $>$.
} 
investigar os protocolos de arquivo e os métodos de classificação dos documentos decorrentes da realização de exposições de arte contemporânea, e analisar o impacto destas práticas na escrita da História da Arte $^{6}$.

Os investigadores do MACBA ligados a este projeto visitaram os museus cujos arquivos consideraram exemplares neste campo. O Centre Pompidou foi uma das instituições visitadas, não só pela extensão do seu arquivo, mas sobretudo pelo estudo que está a desenvolver sobre as exposições realizadas desde a sua fundação.

\subsection{O CATÁLOGO RAISONNÉ DAS EXPOSIÇÕES DO CENTRE POMPIDOU}

Este projeto nasceu de um círculo de reflexão sobre a história das exposições que fora criado no contexto do programa Recherche et mondialisation. Este círculo reunia os responsáveis pelo museu, arquivo e biblioteca do Centre Pompidou, entre outros $^{7}$ e tinha como principal objetivo agilizar o processo de documentação e catalogação das exposições, dando destaque à fortuna crítica relacionada com estes eventos.

Toda esta dinâmica em torno da história das exposições baseou-se numa nova abordagem do evento expositivo. Para os responsáveis do Centre Pompidou a exposição constitui "um objeto cultural em si mesmo, um objeto cuja história é possível traçar através de diversos meios" (Parcollet; Szacka, 2012, p.107).

O estudo sistemático das exposições do Centre Pompidou é ainda sustentado por uma outra ideia, a de que ao analisar-se as suas exposições escreve-se, ao mesmo tempo, a sua história.

A constituição do Catálogo Raisonné de Exposições do Centre Pompidou envolve uma relação estreita entre o Museu, a Biblioteca e o Arquivo desta instituição e uma articulação com o meio acadêmico, através da colaboração com dois centros de investigação, o Laboratoire d'Excellence Création, Arts et Patrimoines (Labex CAP, Université Paris 1 Panthéon-Sorbonne) e o LabexArts $\mathrm{H} 2 \mathrm{H}$ (Université Paris 8) ${ }^{8}$.Esta

\footnotetext{
6 No âmbito deste projeto, os investigadores do MACBA compilaram bibliografia relacionada com a documentação e a historiografia de exposições de arte contemporânea: Disponível em:

<http://www.mela-project.eu/upl/cms/attach/20130613/170804387_7366.pdf>_Acesso em: mar. 2015. A investigação desenvolvida e os resultados da participação do MACBA neste projeto, nomeadamente a recomendação de práticas para o arquivo de documentação de exposições, foram publicados online. Disponível em: <http://www.macba.cat/en/essay-folding-the-exhibition>. Acesso em: mar. 2015.

${ }^{7}$ Catherine Grenier (Centre Pompidou), Didier Schulmann (Bibliothèque Kandinsky), Laurent Le Bom (Centre Pompidou-Metz), Jean-Pierre Criqui (Les Cahiersdu MNAM) Jérôme Glicenstein (Université Paris 8), Manuela Manzini (Musée National d'Art Moderne/ Centre de Création Industrielle).

8 O Catálogue raisonné do Centre Pompidou divulga informações sobre o projeto e as suas atividades através do blog" Histoires des expositions“, Disponível em: <http://histoiredesexpos.hypotheses .org/>. Acesso em: mar. 2015.
} 
relação tem sido fortemente fomentada pelo Centre Pompidou, que está a financiar um programa de bolsas para alunos de doutoramento tendo em vista a especialização na área da história das exposições. Através da organização de seminários e encontros internacionais, o projeto procura ainda promover a constituição de uma rede de investigadores dedicados a este tema.

A equipe que está a trabalhar na catalogação das exposições do Centre Pompidou é composta por arquivistas e investigadores de Doutoramento e PósDoutoramento e por estagiários ligados aos centros de investigação que colaboram no projeto. Apesar de não terem sido ainda disponibilizados os resultados concretos do processo de inventariação, foi divulgada a ficha modelo que está a ser utilizada (Parcollet; Szacka, 2012, p.116-122).

Da análise desta ficha podemos concluir que os vários campos que a integram e o detalhe informativo que o seu preenchimento exige supõem a existência de um suporte documental e bibliográfico bastante completo sobre cada exposição. Ou seja, é necessário que o Arquivo e a Biblioteca institucionais preservem todos os registos relacionados não só com a organização de cada exposição, mas também coma sua receção por parte do público e o impacto no panorama artístico e cultural da época.

Na verdade, são poucas as instituições que poderão levar a cabo um estudo tão sistemático e minucioso sobre as suas próprias exposições. O MACBA realizou, no âmbito do projeto acima referido, um inquérito com o objetivo de avaliar a gestão da documentação gerada pelas exposições. Verificou-se, então, que a maioria das instituições apenas guarda os registos fotográficos e as notícias e artigos publicados na imprensa. Os responsáveis deste estudo concluíram que não é prática corrente a preservação da documentação associada ao processo de organização dos eventos expositivos, como a sua planificação, o registo da montagem, etc. Deste modo, vários materiais necessários para o estudo das exposições estão em risco ou terão mesmo já desaparecido dos arquivos dos museus (Folding the exhibition, 2014, p.14).

\section{O CATÁLOGO RAISONNÉ ONLINE DAS EXPOSIÇÕES DE ARTE DA} FUNDAÇÃO CALOUSTE GULBENKIAN

\subsection{O IMPACTO DA FCG E DAS SUAS EXPOSIÇÕES NO PANORAMA} ARTÍSTICO PORTUGUÊS

A Fundação Calouste Gulbenkian (FCG) é uma das poucas instituições que mantêm os processos originais relativos às exposições organizadas. A riqueza documental do arquivo da Fundação foi uma das primeiras razões para a criação de um 
catálogo raisonné de exposições, à semelhança do que o Centre Pompidou está a preparar.

A exposição 50 anos de Arte portuguesa ${ }^{9}$, realizada em 2007, tornou evidente a importância do material documental decorrente da atividade da FCG para a história da arte portuguesa da segunda metade do século XX. Nesta exposição exibiram-se documentos do Arquivo do Serviço de Belas-Artes $(S B A)^{10}$, sobretudo relacionados com as bolsas atribuídas aos artistas portugueses como os relatórios de atividades que, em muitos casos, assumiram uma dimensão artística. Destacaram-se ainda alguns eventos expositivos organizados pela FCG que tiveram impacto no panorama artístico português, como as três edições da Exposição de Artes Plásticas, realizadas em 1957, 1961 e 1986 ou o ciclo 7 Artistas ao 10 Mês, iniciado em 1996.

Para a preparação desta exposição as comissárias levaram a cabo, pela primeira vez, uma análise do material documental do Serviço de Belas-Artes. Esta primeira abordagem historiográfica da documentação do SBA suscitou o início do seu tratamento arquivístico pelo Projeto Arquivo da Fundação Calouste Gulbenkian, que a partir de 2003, passara a gerir a documentação proveniente dos vários serviços da FCG. Este projeto dera prioridade na incorporação e tratamento documental aos serviços já extintos. O SBA, que só seria extinto em 2010, esteve, portanto, excecionalmente entre os primeiros serviços visados pelo Arquivo da FCG, que, devido à exposição mencionada, procedeu à incorporação e tratamento da sua documentação.

Foi, portanto, no contexto de uma exposição que se tornou clara a relevância da atividade da FCG no panorama artístico português e a necessidade de estudar sistematicamente o seu acervo documental.

Para além do programa de bolsas, a atividade da FCG no campo das artes plásticas, destacou-se também pela organização de exposições. Foi precisamente sobre esta área de intervenção que se debruçaram alguns projetos de investigação mais recentes: duas teses de Doutoramento ${ }^{11}$ e uma visita virtual à Exposição de Artes Plásticas de 1957, criada no âmbito do estudo Fontes para a História dos Museus de

\footnotetext{
9 Exposição realizada na galeria de exposições temporárias do Museu Calouste Gulbenkian, comissariada por Raquel Henriques da Silva, Ana Filipa Candeias e Ana Ruivo.

${ }^{10}$ Aquando da sua criação em 1956, a FCG integrava um único Serviço dedicado às artes plásticas, o Serviço de Museu e Belas-Artes, que associava, deste modo, o trabalho respeitante à coleção Calouste Gulbenkian às atividades de divulgação e apoio às artes plásticas contemporâneas. Em 1961, o Serviço de Belas-Artes autonomizou-se do Serviço de Museu, mantendo-se responsável pela gestão do programa de bolsas a artistas, historiadores e críticos de arte portugueses, e pela organização de exposições.

11 Tese de Doutoramento Leonor de Oliveira, defendida em 2013 na Faculdade de Ciências Sociais e Humanas da Universidade Nova de Lisboa, intitulada Fundação Calouste Gulbenkian: estratégias de apoio e internacionalização da arte portuguesa 1957-1969. André Silveira está a preparar a sua tese de doutoramento sobre a Exposição-Diálogo, realizada em 1985 no Centro de Arte Moderna (v. SILVEIRA, 2014).
} 
Arte em Portuga/12. António Pinto Ribeiro, por seu turno, destacou também as iniciativas expositivasna análise da atividade da FCG no campo das artes, aquando da celebração dos 50 anos da sua constituição (Ribeiro, 2007).

Para além do SBA, a organização de exposições tem sido uma atividade transversal a outros serviços da Fundação: o Museu Calouste Gulbenkian (MCG), o Serviço de Exposições e Museografia (SEM) e o Centro de Arte Moderna (CAM). Outros serviços não relacionados com as artes plásticas, como o Serviço de Música ou a área das Ciências da FCG também desenvolveram projetos expositivos.

Fig.1 Embalagem da obra O Desterrado, no Museu Nacional de Soares dos Reis (Porto), 1967. (C) Foto FCG-BA. Esta foi uma das várias peças expostas em Bruxelas, Paris e Madrid entre outubro de 1967 e maio de 1968, no âmbito da exposição itinerante Arte portuguesa. Escultura e pintura do naturalismo aos nossos dias, organizada pela Fundação Calouste Gulbenkian. Esta imagem constitui um exemplo do importante acervo fotográfico do arquivo da FCG, relacionado com a memória das suas exposições.

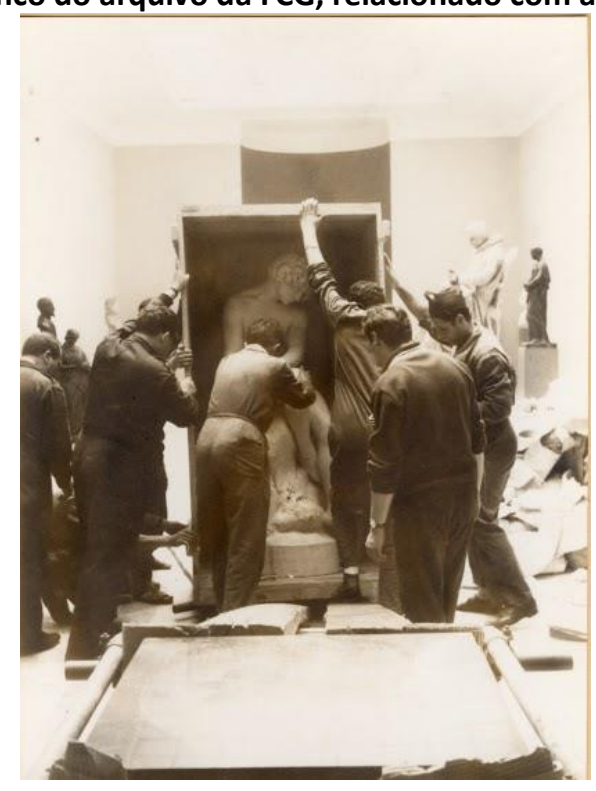

Fonte: Fundação Calouste Gulbenkian - Biblioteca de Arte.

O próprio prestígio e impacto das exposições da FCG justificam a sua análise. No entanto, elas são muito mais do que um fenómeno pontual, podendo ser encaradas como verdadeiros testemunhos da arte e cultura portuguesas e como acontecimentos históricos, marcantes para a promoção e desenvolvimento das práticas e políticas artísticas e culturais e, finalmente, como objetos artísticos em si mesmo(Fig.1).

\footnotetext{
12 Este projeto, financiado pela Fundação para a Ciência e a Tecnologia e coordenado pela Professora Raquel Henriques da Silva (PTDC/EAT-MUS/101463/2008), teve por objetivo o levantamento, estudo e disponibilização de fontes documentais relacionadas com a criação e história dos museus de arte em Portugal. Para a criação da visita virtual à exposição da FCG, estabeleceu-se uma parceria com o Centro de Investigação em Informática e Tecnologias da Informação - CITI, da Faculdade de Ciências e Tecnologia da Universidade Nova de Lisboa. A equipa que responsável pela programação da visita virtual foi liderada pelo Professor Nuno Correia e integrou os investigadores Rui Nóbrega e Carlos Nobre e a designer Bárbara Teixeira (v. SILVA, 2013)
} 
$\mathrm{Na}$ área das artes plásticas, as exposições da FCG constituíram a vertente mais visível e de maior impacto da sua atividade junto do público. Os eventos expositivos manifestavam as políticas de promoção dos jovens artistas e de salvaguarda do património empreendidas pela Fundação. Asseguravam a divulgação da arte internacional no nosso país e o contacto com nomes de referência da produção artística de diversos períodos históricos. A própria FCG procurava projetar-se através das exposições que organizava, disponibilizando significativos recursos para a sua montagem. Estes eventos destacavam-se, por isso, pelo cuidado, qualidade e modernidade das soluções museográficas e pelos programas curatoriais, devido também à intervenção de nomes destacados da arquitetura, artes, design e história da arte portugueses (Fig.2).

Fig.2 Um aspeto da exposição A Rainha D. Leonor, Mosteiro da Madre de Deus, 1958-1959. (C) Foto FCG-BA. A FCG patrocinou as obras de restauro do Mosteiro da Madre de Deus propositadamente para a realização desta exposição, que visava evocar a ação caritativa e mecenática da Rainha, o que coincidia com os próprios fins da Fundação. $O$ arquiteto Francisco Conceição Silva liderou a equipa responsável pela montagem desta exposição. $\mathbf{O}$ grande número de visitantes obrigou a adiar o seu encerramento e a alargar o horário de visita das $21.30 \mathrm{~h}$ às $24 \mathrm{~h}$.

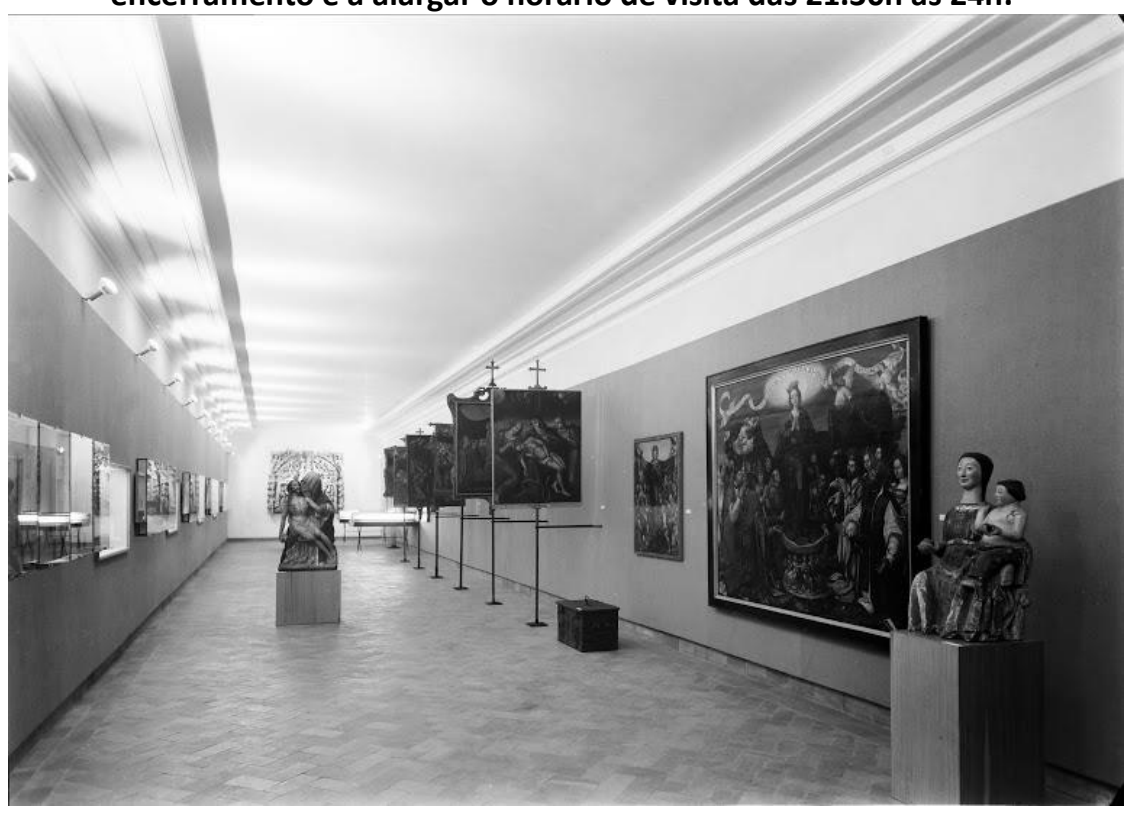

Fonte: Fundação Calouste Gulbenkian - Biblioteca de Arte.

As exposições da FCG constituíram e constituem ainda marcos da cultura e das artes portuguesas. O seu estudo permite ainda acompanhar as várias tendências da produção artística da segunda metade do século XX, rever a historiografia de diversos períodos da arte portuguesa, analisar o acolhimento das tendências artísticas internacionais, e recuperar os discursos relacionados com a preservação patrimonial e promoção artística. Para além disso, sendo a organização de exposições acompanhada de iniciativas educativas, o estudo das exposições da FCG permite também traçar o desenvolvimento dos programas educativos associados à arte. 


\subsection{PRESERVAR A MEMÓRIA. O ESTUDO SISTEMÁTICO DAS EXPOSIÇÕES}

\section{DA FCG}

O projeto Catálogo Raisonné Online das Exposições de Arte da Fundação Calouste Gulbenkian (projeto Rais Expo) visa, em primeiro lugar, a inventariação, estudo e divulgação da memória expositiva da Fundação Calouste Gulbenkian no campo artístico. Mas pretende também explicitar a múltipla valência dos eventos expositivos, procurando ainda participar no debate que está a decorrer a nível internacional sobre a valorização destes eventos na análise crítica da história da arte e ainda contribuir para a definição de metodologias de valorização e patrimonialização das exposições.

O projeto RaisExpo é uma iniciativa da Presidência da FCG. Coordenado por Helena de Freitas, este é um projeto transversal e aberto à colaboração dos diferentes Serviços (ou unidades orgânicas) desta Instituição, que lhe estão tematicamente associados. Por esta razão, estabeleceu-se desde logo uma estreita relação com o Arquivo e a Biblioteca de Arte da FCG. De igual modo, para a concretização deste projeto foi necessária a articulação com o Museu Calouste Gulbenkian e com o Centro de Arte Moderna, que foi imediatamente garantida pelos respetivos diretores.

Os trabalhos arrancaram em dezembro de 2013 através de uma parceria estratégica com o Instituto de História da Arte da Faculdade de Ciências Sociais e Humanas da Universidade Nova de Lisboa (IHA, FCSH/NOVA). Raquel Henriques da Silva, professora nesta faculdade, representa o Instituto na coordenação científica do projeto. Estabelecia-se, deste modo, uma ponte entre a FCG, protagonista de uma ação de extrema relevância no panorama artístico português e detentora de fontes essenciais para documentar a arte portuguesa da segunda metade do século $X X$, e uma unidade de investigação que promove a interpretação e contextualização desse material documental, valorizando-o enquanto fonte para a produção de novo conhecimento e de novos modos de perspetivar a história da arte portuguesa.

Esta parceria está ainda a contribuir para a formação de alunos da Licenciatura em História de Arte e do Mestrado em História da Arte e Museologia, que estão a desenvolver os seus estágios no âmbito deste projeto.

Como foi já referido, o ponto de partida do projeto Rais Expo foi o material de arquivo conservado sobre cada exposição realizada pela FCG. Esse material encontra-se integrado no espólio documental do serviço responsável pela organização da exposição, pelo que foi desde logo importante clarificar a estrutura da FCG e determinar os Serviços que tinham produzido eventos expositivos (Fig. 3). Uma 
primeira decisão relacionou-se com a multiplicidade e diversidade temática das exposições realizadas pela FCG que obrigou este estudo a cingir-se às exposições de arte. Não serão, por isso, analisadas, pelo menos numa primeira fase do trabalho, as exposições exclusivamente ligadas às áreas da Música, da Ciência ou Literatura.

Fig.3 Os cartazes são outros testemunhos da actividade expositiva da FCG. Na imagem, cartaz concebido pelo designer Sebastião Rodrigues para a exposição Arte do Índio Brasileiro, 1966. A exposição realizou-se na Sociedade Nacional de Belas-Artes (Lisboa) e foi organizada pela Fundação Calouste Gulbenkian com a colaboração da Embaixada do Brasil em Lisboa.

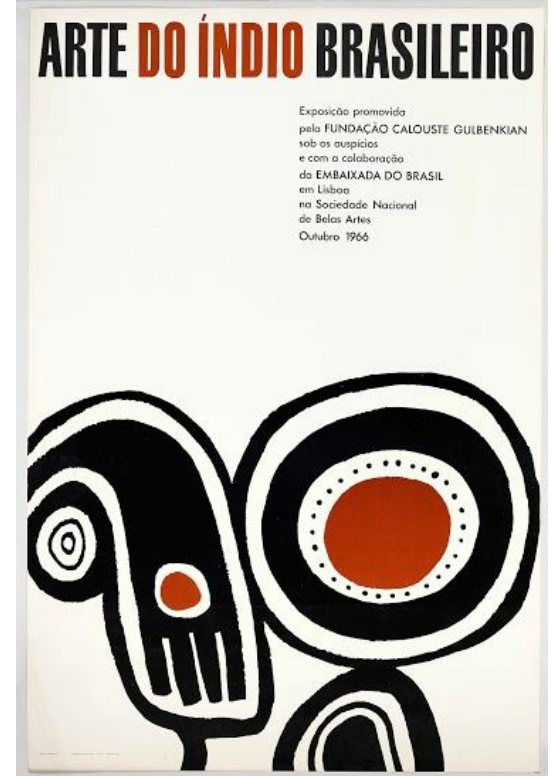

Fonte: Fundação Calouste Gulbenkian - Biblioteca de Arte.

Fig.4 Vista da exposição Almada Negreiros e o espectáculo, Centro de Arte Moderna, 1984. C Foto FCG-CAM. José de Almada Negreiros foi o artista escolhido para a exposição comemorativa do 10 aniversário do Centro de Arte Moderna e do 280 aniversário da Fundação. Tratou-se de uma exposição retrospetiva que procurou ser o mais completa possível e apresentar as diferentes tipologias do trabalho do artista. Foram expostas obras inéditas e divulgou-se a pluridisciplinaridade do percurso de Almada Negreiros nas áreas do espetáculo, teatro e bailado.

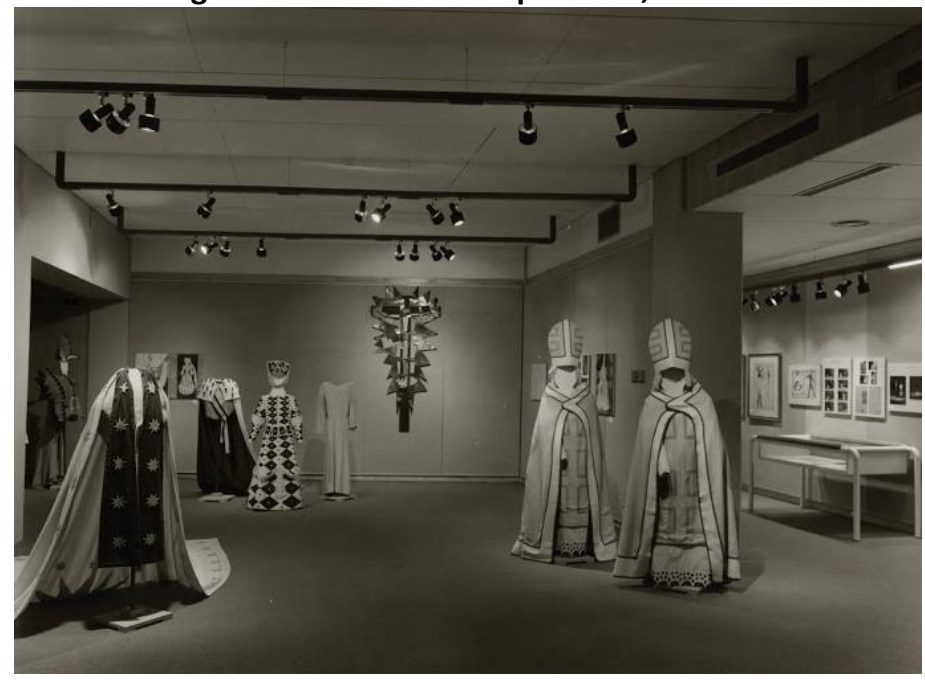

Fonte: Fundação Calouste Gulbenkian - Centro de Arte Moderna. 
Uma segunda decisão prendeu-se com a seleção dos Serviços cuja atividade expositiva seria analisada em primeiro lugar.

O SBA assumiu desde logo prioridade, dada a importância da sua ação no panorama artístico português, o facto de ter sido o primeiro Serviço a organizar exposições e, por fim, porque a sua documentação já se encontra catalogada pelo Arquivo da FCG. Optou-se também por se estudar desde logo as exposições do CAM, abrangendo assim uma cronologia mais recente e um serviço que veio afirmar a participação da FCG no panorama da arte portuguesa contemporânea e na preservação da memória da produção artística nacional de todo o século XX (Fig. 4). Aquando do início deste projeto, o espólio documental do CAM mantinha-se autónomo, ou seja, não tinha sido ainda integrado no Arquivo da FCG e sujeito a catalogação. Esta situação alterou-se entretanto graças ao desenvolvimento da investigação levada a cabo no âmbito do projeto Rais Expo.

Tendo por base o projeto do Centre Pompidou, e a consequente aproximação do evento expositivo a um objeto inventariável, definiu-se a ficha que seria preenchida com os dados de cada exposição. Esta ficha baseia-se nos campos identificados pelos investigadores do Raisonné do Centre Pompidou, mas foi adaptada aos interesses da investigação e ao contexto específico das exposições da FCG.

$\mathrm{Na}$ verdade, existem diferenças significativas entre a atividade expositiva da FCG e a do Centre Pompidou. Em primeiro lugar, a FCG tem uma história mais longa que o Pompidou - foi criada em 1956, tendo organizado a sua primeira exposição em 1957, enquanto que o Pompidou abriu portas em 1977. As exposições da FCG abrangem várias cronologias da produção artística portuguesa e internacional, centrando-se o Pompidou apenas na arte produzida no século XX e XXI. Em termos de estrutura, a FCG integra vários serviços ligados à produção de exposições, que atuam não só em Portugal, mas também no estrangeiro. O caso da FCG é, portanto, bastante particular e poderá servir de modelo a projetos relacionados com instituições que tenham uma natureza semelhante.

Apesar da complexa estrutura e atividade expositiva da FCG, a ficha de exposição do seu catálogo raisonnéé mais concisa, tendo-se selecionado a informação indispensável para a caracterização de cada exposição e optado por campos mais abrangentes em termos de informação. Definiram-se ainda campos de acesso público e campos de acesso reservado.

A inventariação das exposições da FCG atingiu uma segunda fase no momento em que se passou para a sua integração em base de dados informática. Optou-se por adaptar a base de dados In Arte, que servia o inventário da coleção do Museu Calouste Gulbenkian e do Centro de Arte Moderna, e que continha já uma tarefa dedicada às 
Exposições. Em colaboração com a empresa responsável por esta aplicação, a Sistemas do Futuro, adaptaram-se os campos já existentes e adicionaram-se novos campos conforme as necessidades do projeto. Alguns dos dados já recolhidos puderam ser acomodados nos campos que a base de dados já dispunha.

O recurso a uma base de dados já existente, que não era vocacionada diretamente para a inventariação de exposições, deveu-se, por um lado, ao facto de ela ser já utilizada na FCG e, por outro, isso permitir a partilha de informações sobre as obras de arte, bibliografia ou mesmo exposições já registadas no In Arte. A utilização da mesma base de dados possibilita, portanto, uma articulação e complementaridade entre o estudo da atividade expositiva da FCG e o modo como as suas coleções de arte, do MCG e do CAM, têm sido exibidas ao longo dos anos e recebidas pelo público. Esta opção torna também possível documentar a incorporação de obras de arte através de exposições, no caso da coleção do CAM. Finalmente, o facto da inventariação de exposições estar incorporada numa base de dados comum aos Serviços que, para além de gerirem coleções, são também os principais produtores de exposições, permitirá a inventariação imediata de uma exposição e a integração de informação durante o processo de organização. Este projeto definiu não só a informação necessária a integrar sobre cada exposição mas também as normas de preenchimento da ficha, que serão disponibilizadas a todos os inventariantes.

O acesso público a esta base de dados será feitoonline, através de um site que disponibilizará o Catálogo Raisonné das Exposições de Arte da FCG. Será entãopermitida a consulta não só da ficha de inventário de cada evento, mas também de dados gerais, mais estatísticos, sobre o conjunto das exposições organizadas por esta instituição: locais (em sistema de geo-referenciação), instituições parceiras, quadro cronológico, temas, artistas participantes, etc.

Após a implementação do site, prevista para 2016, os dados serão disponibilizados de modo progressivo, acompanhando o avanço da investigação.

A conclusão deste projeto está prevista para 2019, ano que comemora o 50응 aniversário da inauguração da Sede e Museu da FCG e em que será organizada uma exposição ou ciclo de exposições que darão a conhecer os resultados deste projeto.

\section{CONCLUSÃO}

Até muito recentemente, eram sobretudo as exposições promovidas pelo Estado Novo, com fins políticos e propagandísticos, que mereciam a atenção dos investigadores portugueses. Ao estudar sistematicamente as exposições de arte produzidas pela FCG, o projeto Rais Expo pretende não só valorizar estes eventos e 
destacar o seu papel no panorama artístico e na História da Arte, mas também explicitar a sua dimensão artística. A relação estabelecida entre um conteúdo/ discurso específico e um aparato visual que o torna acessível ao público particulariza o evento expositivo e torna pertinente não só o seu estudo, mas também a preservação da sua memória.

O Catálogo Raisonné Online das Exposições da Fundação Calouste Gulbenkian segue já exemplos internacionais de patrimonialização de exposições, como o Raisonné que está a ser elaborado pelo Centre Pompidou. No entanto, o projeto da FCG acrescenta novas questões e conteúdos ao debate internacional dada a transversalidade de temáticas e de cronologias evocadas pelas suas exposições, que dão a conhecer não só a exibição e receção da produção artística contemporânea, mas também a valorização e acolhimento de obras, autores e períodos artísticos anteriores ao século $X X$.

\section{REFERÊNCIAS}

50 Anos de Arte Portuguesa. Lisboa: Fundação Calouste Gulbenkian. Serviço de Belas-Artes. Centro de Arte Moderna José de Azeredo Perdigão, 2007.

FOLDING the exhibition. Barcelona: MCBA, 2014. Disponível em:

<http://www.macba.cat/en/essay-folding-the-exhibition>.Acesso em: mar. 2015.

HARALD Szeemann with by through because towards despite: catalogue of all exhibitions, 1957-2005. Zürich: Voldemeer; Wien: Springer, 2007.

OLIVEIRA, Leonor de.Fundação Calouste Gulbenkian: estratégias de apoio e internacionalização da arte portuguesa 1957-1969. Tese (Doutorado).Faculdade de Ciências Sociais e Humanas da Universidade Nova de Lisboa, Lisboa, 2013.[texto policopiado].

PARCOLLET, Rémi ;Szacka, Léa-Catherine. Histoiredesexpositionsdu Centre Pompidou: réflexionssur la constitution d'un catalogue raisonné. In Marges, revue d’artcontemporain. Démocratiserl'art (contemporain),v.15, p. 107-127, 2012.

RIBEIRO, António Pinto. Arte:um ministério das artes: das belas-artes, das exposições, dos subsídios, do teatro, do cinema e das bolsas. In:Fundação Calouste Gulbenkian: cinquenta anos, 1956-2006. Lisboa: Fundação Calouste Gulbenkian, 2007.p. 237-408.

SILVA, Raquel H.; BAIÃO, Joana; OLIVEIRA, Leonor de, (eds). Projetha: projects of the Institute of History of Art. Sources for the History of Art Museums in Portugal - final report.Lisboa: Instituto de História da Arte-FCSH/NOVA, 2013. 
SILVEIRA, André. Exposição-Diálogo: a procura de uma identidade europeia.In: $\mathbf{3 0}$ anos/years:

Centro de Arte Moderna Fundação Calouste Gulbenkian. Lisboa: FundaçãoCalousteGulbenkian.

Centro de Arte Moderna, 2014.p. 172-184 